\title{
Maternal Near Miss: Data from a Tertiary Care Hospital of Lahore
}

\author{
Sardar Muhammad Alfareed Zafar ${ }^{1}$, Maryam Javed ${ }^{2}$, Mehwish $l l y a s,{ }^{3}$ Muhammad Azeem Mughal ${ }^{4}$
}

1,2,3Department of Gynecology \& Obstetrics, Lahore General Hospital, Lahore-Pakistan, 4 Kidney \& Transplantation Department, Pakistan Kidney and Liver Institute Lahore-Pakistan

\begin{abstract}
Background: Death or near to death of a woman during pregnancy or within 42 days after end of pregnancy due to any obstetric cause is known as maternal near-miss. Objective: To determine the frequency of causes and surgical interventions conducted to manage the pregnant females presented with maternal near-miss. Study Design: Cross sectional study. Settings: Department of Obstetrics \& Gynecology, General Hospital, Lahore Pakistan. Duration: 3 months from January 01, to March 30, 2019. Methodology: Sample size of 84 patients were enrolled in the study through non-probability, consecutive sampling. Patients of age 15-45 years, presented after 12 weeks of pregnancy with maternal near-miss. Then patients underwent medical or surgical procedure for management of maternal near-miss. Results: The mean age of patients was $33.93 \pm 13.95$ years. The mean gestational age at time of maternal near-miss was $24.58 \pm 7.93$ weeks. The most common cause of maternal near-miss was eclampsia [33 (39.2\%)], followed by ruptured ectopic [23 (27.3\%)], morbidly adherent placenta [11 (13\%)], uterine rupture [7 (8.5\%)] and septic induced [1 (1.2\%)]. Cases of ruptured uterus underwent surgical procedure. Most commonly, peri-partum hysterectomy was performed i.e. $13(15 \%)$ cases followed by B-lynch [10 (11.9\%)] and uterine atony [1 $(1.2 \%)]$. Conclusion: The frequency of need of severe complications like eclampsia was high in such cases. Now, we have got the local evidence and now we recommend the females for regular antenatal check-up in pregnancy and screening for such complications in earlier stages to avoid such complications and maternal near-miss in future.
\end{abstract}

Keywords: Maternal near miss, Obstetrics complications, Life-threatening conditions.

Corresponding Author Submitted for Publication: 11-05-2020

Dr. Sardar Muhammad Alfareed Zafar, Professor of Gynecology \& Obstetrics, Lahore General Hospital, Lahore-Pakistan

Email: alfareedivf@hotmail.com

Citation: Zafar SMA, Javed M, llyas M. Maternal Near Miss: Data from a Tertiary Care Hospital of Lahore. APMC 2020;14(3):214-7.

\section{DOI: 10.29054/APMC/2020.931}

\section{INTRODUCTION}

Each year, an estimated 529,000 maternal deaths occur worldwide. In literature, it is known that maternal mortality can occur during pregnancy, peripartum and also in postpartum period. ${ }^{1}$ Maternal mortality is one of the important indicators used for the measurement of maternal health. Although maternal mortality ratio remains high, maternal deaths in absolute numbers are rare in a community. To overcome this challenge, maternal near miss has been suggested as a compliment to maternal death. ${ }^{2}$ Reliable information about the rates and trends in maternal mortality is essential for resource mobilization, and for planning and assessment of progress towards Millennium Development Goal 5 , the target for which is a $75 \%$ reduction in the maternal mortality ratio from 1990 to $2015 .^{3}$

Severe maternal morbidity or "near miss" is a promising indicator to improve quality of obstetric care. ${ }^{4}$ The World Health Organization definition enables a common ground for the implementation of maternal near-miss assessments across countries and allows international comparisons to be carried out. 5,6 Different studies have reported controversial results. The rate of near miss was ranged from $0.33 \%$ to $12 \% .{ }^{7-10}$ Among these cases, the rate of still birth was reported to be high i.e. $11.2 \%$ to $28.4 \% .8,10$ Maternal near misses are increasingly used to study quality of obstetric care. Inclusion criteria for the identification of near misses are diverse and studies not comparable. World Health Organization developed universal near miss inclusion criteria in 2009 and these criteria have been validated in Brazil and Canada. ${ }^{11}$

According to a study conducted in Sudan, during the 2016, there were 994 deliveries, 94 near-misses, and 10 maternal deaths. This resulted in maternal near-miss and mortality rates of 94.1 per 1,000 and 1,007 per 100,000 live births, respectively. Severe maternal outcome and maternal near-miss rates were 10.47 per 1,000 (morbidity-based criteria) and 41.3 per 1,000 (organ failure-based criteria), respectively. ${ }^{12}$ Applicability of the World Health Organization maternal near miss criteria in lowincome settings is not systematically addressed in the literature. ${ }^{13}$ The aim of the study is to determine the causes and surgical interventions conducted to manage the pregnant females presented with maternal near-miss. It has been observed that maternal near miss can be dreadful. With changing lifestyle and less use of antenatal care increasing which lead to complications of pregnancy and to maternal nearmiss. So, this study was done to determine the outcome of management of maternal near-miss in a tertiary care hospital of Lahore.

\section{METHODOLOGY}

Study Design: Cross sectional study.

Settings: Department of Obstetrics \& Gynecology, Lahore General Hospital, Lahore-Pakistan.

Duration: 3 months i.e. from January 01, to March 30, 2019. Sample Technique: Non-Probability, Consecutive Sampling. 
Sample Size: Data of 84 cases was included in the study presented with maternal near miss during 3 months.

Inclusion Criteria: Patients of age 15-45 years, presented after 12 weeks of pregnancy with maternal near-miss. It was defined as "a woman who nearly died but survived a complication that occurred during pregnancy, childbirth or within 42 days of termination of pregnancy", as defined by World Health Organization.

Exclusion Criteria: Chronic conditions including diabetes, hypertension, renal dysfunction, bleeding disorders, accidental cases presenting in emergency.

Methods: 84 patients fulfilling the above-mentioned inclusion criteria were enrolled in this study from emergency. Informed consent was obtained and patient demographic information was recorded. Then patients underwent medical or surgical procedure for management of maternal near-miss. All cases were done by a consultant obstetrician with assistance of researcher. The procedures performed to manage such cases were noted. Data was recorded on proforma and analyzed by using SPSS version 21.0.

\section{RESULTS}

The mean age of patients was $33.93 \pm 13.95$ years. The mean gestational age at time of maternal near-miss was $24.58 \pm 7.93$ weeks. Table 1

Table 1: Demographics of patients

\begin{tabular}{|l|l|}
\hline $\mathbf{N}$ & 84 \\
\hline Age (yeas) & $33.93 \pm 13.95$ \\
\hline Gestational age (weeks) & $24.58 \pm 7.93$ \\
\hline
\end{tabular}

The most common cause of maternal near-miss was eclampsia [33 (39.2\%)], followed by ruptured ectopic [23 (27.3\%)], morbidly adherent placenta [11 $(13 \%)]$, uterine rupture [7 $(8.5 \%)]$ and septic induced [1 (1.2\%)]. Table 2

Table 2: Causes of maternal near-miss

\begin{tabular}{|l|l|}
\hline Maternal near-miss & 84 \\
\hline Eclampsia & $33(39.2 \%)$ \\
\hline Ruptured ectopic & $23(27.3 \%)$ \\
\hline Morbidly adherent placenta & $11(13 \%)$ \\
\hline Uterine rupture & $7(8.5 \%)$ \\
\hline Septic induced & $1(1.2 \%)$ \\
\hline
\end{tabular}

Cases of ruptured uterus underwent surgical procedure. Most commonly, peri-partum hysterectomy was performed i.e. 13 $(15 \%)$ cases followed by B-lynch [10 (11.9\%)] and uterine atony [1 (1.2\%)]. Figure 1

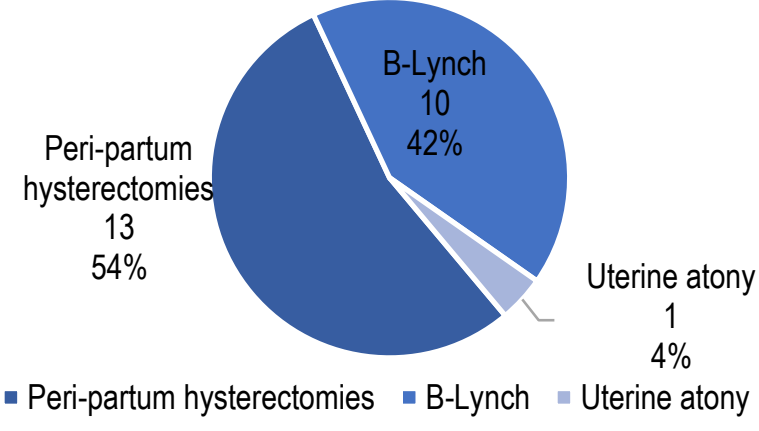

Figure 1: Surgical procedures performed to manage maternal near-miss

\section{DISCUSSION}

Mother and child constitute a large, vulnerable, and a priority group as the risk is involved with childbearing in women and of growth and development in children. For every woman who dies from pregnancy or childbirth-related causes, it is estimated that twenty more suffer from pregnancy-related illness or experience other severe complications. ${ }^{14}$ Maternal mortality and near-miss index reflect the quality of care provided by a health facility. The World Health Organization recently published near-miss approach where strict near- miss criteria based on markers of organ dysfunction are defined. ${ }^{15}$

In our study, the most common cause of maternal near-miss was eclampsia [33 (39.2\%)], followed by ruptured ectopic [23 $(27.3 \%)]$, morbidly adherent placenta [11 (13\%)], uterine rupture [7 (8.5\%)] and septic induced [1 (1.2\%)]. Eclampsia was the most frequent hypertensive disorder (30.9\%), with an MNM ratio of 16.9/1000 Lbs. However, severe preeclampsia and hemolysis, elevated liver enzymes, low platelet count (HELLP) syndrome has been reported in some studies as the most frequent event among hypertensive disorders. ${ }^{16-18}$

Comparing the major causes of near-miss cases and maternal deaths, obstetric hemorrhage and hypertension were the most common underlying causes of severe maternal outcomes, which is comparable to other studies in developing countries. ${ }^{19}$

The severe maternal morbidity: mortality ratio is a possible new indicator of maternal care and could be used to compare improvements in treatments more accurately than mortality data alone. Over 1 in 100 pregnant women suffer a life-threatening event, and there are 118 events for each direct maternal death, most of which are related to obstetric hemorrhage and pre-eclampsia. This major health risk to childbearing women has been relatively under-investigated. Severe obstetric morbidity is measurable and may be a more meaningful way to measure improvements in health care. ${ }^{20}$

There are, however, widely recognized difficulties in the measurement of maternal mortality, including low numbers of deaths and large ranges of uncertainties. Furthermore, fear of blame for a woman's death can affect the levels of cooperation from care providers in both epidemiologic surveillance and in clinical audits. ${ }^{21}$ 
A total of 82 studies from 46 countries were included. Criteria for identification of cases varied widely. Prevalence rates varied between 0.6 and $14.98 \%$ for disease-specific criteria, between 0.04 and $4.54 \%$ for management-based criteria and between 0.14 and $0.92 \%$ for organ-based dysfunction based on Mantel criteria. The rates are higher in low-income and middle-income countries of Asia and Africa. Based on meta-analysis, the estimate of near miss was $0.42 \%(95 \% \mathrm{Cl} 0.40-0.44 \%)$ for the Mantel (organ dysfunction) criteria and $0.039 \%(95 \% \mathrm{Cl} 0.037$ $0.042 \%$ ) for emergency hysterectomy. The meta-regression results indicate that emergency hysterectomy rates have been increasing by about $8 \%$ per year. ${ }^{4}$

Maternal mortality is still among the worst performing health indicators in resource-poor settings. For deaths occurring in health facilities, it is crucial to understand the processes of obstetric care in order to address any identified weakness or failure within the system and take corrective action. However, although a significant public health problem, maternal deaths are rare in absolute numbers especially within an individual facility. ${ }^{22}$

The World Health Organization recommends that the MNM approach be considered in national plans to improve maternal health, because researchers agree that MNMs are frequently a preventable precursor of maternal mortality. ${ }^{23}$ Using the same classification, countries and regions of the same country can be compared to help identify deficiencies in the healthcare system, improve the quality of care during the pregnancy-puerperal cycle and guide more recent studies on the topic. ${ }^{24}$

The applicability of the World Health Organization near miss criteria depends on the local context, e.g. level of health care. The clinical criteria showed good validity. Lowering the threshold for blood transfusion from five to two units in settings without blood bank and addition of disease-based criteria in lowresource settings is recommended. ${ }^{11}$

The audit of maternal near-miss cases is an approach also used in several high-income settings: UK has a well-established program of confidential enquiries into maternal deaths and a national system for research on maternal near-miss-the UK Obstetric Surveillance System (UKOSS);25,26 New Zealand established a national system for severe maternal morbidity review; ${ }^{27}$ several countries within the International Network of Obstetric Survey Systems (INOSS) are collecting data on severe maternal morbidities for study purposes..$^{28}$ Although there are some differences in the type of interventions applied (eg, not all of these approaches are facility-based), still the existence of these large networks on maternal near-miss case reviews and the amount of resources devoted to them somehow testify the importance recognized in reviewing near-miss cases. $^{29}$

\section{CONCLUSION}

The frequency of need of severe complications like eclampsia was high in such cases. Now, we have got the local evidence and now we recommend the females for regular antenatal check-up in pregnancy and screening for such complications in earlier stages to avoid such complications and maternal near- miss in future. Also, there is a need to conduct further studies to determine the outcome of such cases with improved surgical or medical management protocols.

\section{LIMITATIONS}

Study was carried out on eighty-four females only a cross sectional study. However, authenticity of results can improve with larger sample size and more findings can be elaborated. Only few causes and type of surgical procedures were noted, but not the outcome of prognosis of these cases as patients were follow-up for short period.

\section{SUGGESTIONS / RECOMMENDATIONS}

Further studies are recommended with large ample size and cohort / case control studies or interventional studies should be done to determine the short and long term outcome of surgical procedures in such cases with complications.

\section{CONFLICT OF INTEREST / DISCLOSURE}

No conflict of interest to be declared by any author involved in the research.

\section{ACKNOWLEDGEMENTS}

We are grateful to our patients who participated in this study.

\section{REFERENCES}

1. Avcioglu SN, Altinkaya SÖ, Küçük M, Zafer E, Sezer SD, Yüksel $\mathrm{H}$. Second trimester abortion as a cause of maternal death: a case report. Pan Afr Med J. 2015;22:261.

2. Chhabra P. Maternal near miss: an indicator for maternal health and maternal care. Indian J Community Med. 2014;39(3):132-7.

3. Hogan MC, Foreman KJ, Naghavi M, Ahn SY, Wang M, Makela SM, et al. Maternal mortality for 181 countries, 1980-2008: a systematic analysis of progress towards Millennium Development Goal 5. The Lancet. 2010;375(9726):1609-23.

4. Tunçalp Ö, Hindin M, Souza J, Chou D, Say L. The prevalence of maternal near miss: a systematic review. BJOG: An Int J Obs \& Gynaecolo. 2012;119(6):653-61.

5. Say L, Souza JP, Pattinson RC. Maternal near miss--towards a standard tool for monitoring quality of maternal health care. Best Pract Res Clin Obstet Gynaecol. 2009;23(3):287-96.

6. Souza JP, Cecatti JG, Haddad SM, Parpinelli MA, Costa ML, Katz $\mathrm{L}$, et al. The WHO Maternal Near-Miss Approach and the Maternal Severity Index Model (MSI): Tools for Assessing the Management of Severe Maternal Morbidity. PLoS One 2012;7(8):e44129.

7. Goffman D, Madden RC, Harrison EA, Merkatz IR, Chazotte C. Predictors of maternal mortality and near-miss maternal morbidity. J Perinatol. 2007;27(10):597-601.

8. Souza J, Cecatti J, Parpinelli M, Serruya S, Amaral E. Appropriate criteria for identification of near-miss maternal morbidity in tertiary care facilities: a cross sectional study. BMC Pregnancy Childbirth. 2007;7(1):20-8.

9. Mustafa R, Hashmi H. Near-miss obstetrical events and maternal deaths. J Coll Physicians Surg Pak. 2009;19(12):781-5.

10. Adeoye IA, Onayade AA, Fatusi AO. Incidence, determinants and perinatal outcomes of near miss maternal morbidity in lle-lfe 
Nigeria: a prospective case control study. BMC Pregnancy Childbirth. 2013;13(1):93-103.

11. Nelissen E, Mduma E, Broerse J, Ersdal H, Evjen-Olsen B, van Roosmalen J, et al. Applicability of the WHO Maternal Near Miss Criteria in a Low-Resource Setting. PLOS ONE 2013;8(4):e61248.

12. Alemu FM, Fuchs MC, Martin Vitale T, Abdalla Mohamed Salih M. Severe maternal morbidity (near-miss) and its correlates in the world's newest nation: South Sudan. Int J Womens Health. 2019;11:177-90.

13. Tura AK, Trang TL, van den Akker T, van Roosmalen J, Scherjon $\mathrm{S}$, Zwart J, et al. Applicability of the WHO maternal near miss tool in sub-Saharan Africa: a systematic review. BMC Pregnancy Childbirth 2019;19(1):79-88.

14. Kalhan M, Singh S, Punia A, Prakash J. Maternal Near-Miss Audit: Lessons to Be Learnt. Int J Appl Basic Med Res. 2017;7(2):85-87.

15. Sangeeta G, Leena W, Taru G, Sushma K, Nupur G, Amrita P. Evaluation of severe maternal outcomes to assess quality of maternal health care at a tertiary center. J Obstet Gynaecol India. 2015;65(1):23-7.

16. Nakimuli A, Nakubulwa S, Kakaire O, Osinde MO, Mbalinda SN, Nabirye RC, et al. Maternal near misses from two referral hospitals in Uganda: a prospective cohort study on incidence, determinants and prognostic factors. BMC Pregnancy Childbirth. 2016;16:24-9.

17. Oliveira LC, da Costa AA. Maternal near miss in the intensive care unit: clinical and epidemiological aspects. Revista Brasileira de terapia intensive. 2015;27(3):220-7.

18. De Souza MA, De Souza TH, Goncalves AK. [Determinants of maternal near miss in an obstetric intensive care unit]. Rev Bras Ginecol Obstet. 2015;37(11):498-504.

19. Jabir M, Abdul-Salam I, Suheil DM, Al-Hilli W, Abul-Hassan S, AlZuheiri $A$, et al. Maternal near miss and quality of maternal health care in Baghdad, Iraq. BMC Pregnancy Childbirth. 2013;13:1120.

20. Nelissen EJT, Mduma E, Ersdal HL, Evjen-Olsen B, van Roosmalen JJM, Stekelenburg J. Maternal near miss and mortality in a rural referral hospital in northern Tanzania: a crosssectional study. BMC Pregnancy Childbirth. 2013 2013;13(1):141-9.

21. Rööst M, Altamirano V, Liljestrand J, Essén B. Priorities in emergency obstetric care in Bolivia-maternal mortality and near-miss morbidity in metropolitan La Paz. BJOG: An Int J Obs \& Gynaecol. 2009;116(9):1210-7.

22. Say L, Souza JP, Pattinson RC. Maternal near miss - towards a standard tool for monitoring quality of maternal health care. Best Pract Res Clin Obstet Gynaecol. 2009;23(3):287-96.

23. Hirshberg A, Srinivas SK. Epidemiology of maternal morbidity and mortality. Semin Perinatol. 2017;41(6):332-7.

24. De Lima THB, Amorim MM, Buainain Kassar S, Katz L. Maternal near miss determinants at a maternity hospital for high-risk pregnancy in northeastern Brazil: a prospective study. BMC Pregnancy Childbirth 2019;19(1):271-85.

25. Knight M, Lewis G, Acosta CD, Kurinczuk JJ. Maternal near-miss case reviews: the UK approach. BJOG: An Int J Obs \& Gynaecol. 2014;121(4):112-6.

26. Knight M, Acosta C, Brocklehurst P, Cheshire A, Fitzpatrick K, Hinton $L$, et al. Beyond maternal death: improving the quality of maternal care through national studies of 'near-miss' maternal morbidity: National Institute for Health Research2016.
27. MacDonald EJ, Geller SE, Lawton B. Establishment of a national severe maternal morbidity preventability review in New Zealand. Int J Gynaecol Obstet. 2016;135(1):120-3.

28. Knight M, INOSS. The International Network of Obstetric Survey Systems (INOSS): benefits of multi-country studies of severe and uncommon maternal morbidities. Acta Obstet Gynecol Scand. 2014;93(2):127-31.

29. Lazzerini M, Richardson S, Ciardelli V, Erenbourg A. Effectiveness of the facility-based maternal near-miss case reviews in improving maternal and newborn quality of care in lowincome and middle-income countries: a systematic review. BMJ Open. 2018;8(4):e019787.

\section{AUTHORSHIP CONTRIBUTION}

\begin{tabular}{|l|l|}
\hline Dr. Sardar Muhammad Alfareed Zafar & \\
Professor of Gynecology \& Obstetrics, & Supervision \\
Lahore General Hospital, Lahore & \\
Pakistan & Dr. Maryam Javed \\
Senior Registrar of Gynecology \& & Data Collection \\
Obstetrics, Lahore General Hospital, & \\
Lahore Pakistan & \\
\hline Dr. Mehwish llyas & \\
Senior Registrar of Gynecology \& & Manuscript Writing \\
Obstetrics, Lahore General Hospital, & \\
Lahore Pakistan & \\
\hline Dr. Muhammad Azeem Mughal & \\
Senior Registrar, Kidney \& & Statistical Analysis \\
Transplantation, Pakistan Kidney and & \\
Liver Institute Lahore Pakistan & \\
\hline
\end{tabular}

